\title{
Potential Roles of Fatty Acids and Lipids in Postharvest Needle Abscission Physiology
}

\author{
Gaye E. MacDonald1, Rajasekaran R. Lada1', Claude D. Caldwell1', Chibuike Udenigwe², \\ Mason T. MacDonald ${ }^{*}$ \\ ${ }^{1}$ Department of Plant, Food, and Environmental Sciences, Faculty of Agriculture, Dalhousie University, \\ Halifax, Canada \\ ${ }^{2}$ School of Nutrition Sciences, Faculty of Health Sciences, University of Ottawa, Ottawa, Canada \\ Email: *mason.macdonald@dal.ca
}

How to cite this paper: MacDonald, G.E., Lada, R.R., Caldwell, C.D., Udenigwe, C. and MacDonald, M.T. (2019) Potential Roles of Fatty Acids and Lipids in Postharvest Needle Abscission Physiology. American Journal of Plant Sciences, 10, 1069-1089. https://doi.org/10.4236/ajps.2019.106078

Received: May 18, 2019

Accepted: June 25, 2019

Published: June 28, 2019

Copyright (c) 2019 by author(s) and Scientific Research Publishing Inc. This work is licensed under the Creative Commons Attribution International License (CC BY 4.0).

http://creativecommons.org/licenses/by/4.0/

\begin{abstract}
Our understanding of postharvest needle abscission physiology in conifers has greatly improved in the last decade. Abscission is initially triggered by root detachment, which begins a cascade of changes such as decreased water uptake, water potential, and auxins and increased membrane injury, ethylene, abscisic acid, volatile terpenes, and catalytic enzymes. Needle abscission is also affected by environmental factors. For example, a period of cold acclimation generally delays postharvest abscission. The aforementioned pieces of evidence, along with previous studies, strongly points to a role for plant lipids and fatty acids. Studies from other species have pointed out key roles in abscission and stress responses for a variety of phospholipids and galactolipids, which has not been studied in balsam fir. It is imperative to have an understanding of the role of plant lipids and fatty acids to further our overall understanding of the physiological mechanisms of postharvest abscission and needle abscission resistance. This review is an overview of membrane lipids and fatty acids, changes that occur postharvest and the interaction that lipids may have in the phenomenon of postharvest abscission.
\end{abstract}

\section{Keywords}

Phospholipids, Galactolipids, Fatty Acids, Plant Growth Regulators, Abscission

\section{Introduction}

Unlike animals, plants are unable to move from adverse environments and lack sense organs such as eyes and ears. Plants sense stimuli from their environment through disturbances or changes in membranes. Biotic and abiotic stressors can 
alter cell membrane structure and composition.

Root detachment is necessary for the harvesting of many plants. With respect to conifers, root detachment deprives needles from root-derived factors. Detachment of roots results in various stresses such as wounding, anoxia, nutritional starvation, and dehydration, which can be detected by the cell membrane [1] [2] [3]. Survival of cells postharvest depends on maintaining membrane homeostasis and a plant's ability to adapt to stress. Severe membrane perturbation can lead to cell death or senescence [4]. Another stress response in root detached balsam fir is organ abscission due to the loosening and separation of the cells in the abscission zone, primarily due to the breakdown of the cell wall by the action of enzymes such as cellulose [5]. Abscission generally follows senescence, though senescence is not a prerequisite for postharvest needle abscission [6].

The main components of biological membranes are lipids. Recently, lipids and fatty acids (FAs) have been found to be signaling molecules and/or precursors giving rise to other molecules related to abscission and/or senescence [7]. The two primary lipids reviewed within this document are glycerolipids, with emphasis on phospholipids (PLs), and galactolipids (GLs). PLs are the primary membrane lipids, whereas GLs tend to be associated mostly with the chloroplast membranes [8]. Only through identifying the current established physiological pathways for postharvest needle abscission and lipidsignaling can the potential role(s) for lipids and fatty acids being established.

\section{Abscission in Plants}

Balsam fir Christmas trees are harvested by detaching them from their roots, depriving the stems and needles from root-derived factors. The harvesting process places the tree under multiple stresses and it has been found that abscission of needles is a postharvest quality challenge. Wounding creates the initial stress postharvest but the most predominant stress is water deficit or drought, even when the root-detached trees are rehydrated [1] [6] [9]. Dehydration leads to senescence in balsam fir [10], though individual genotypes demonstrate differences in the level of dehydration required to induce an irreversible response [11].

Abscission is part of the plant development process, which results in release of entire organs, such as leaves or needles, flowers, flower parts such as petals, anthers, seeds, and fruits from the main body of the plant. This is an adaptation to shed non-functioning, damaged or infected organs, or to make possible the fall of fruit and dispersion of seeds [12] [13]. Based on the information available in angiosperms, abscission usually occurs in a band of densely packed cells, referred to as the abscission zone (AZ), varying from a few to many cells thick at the junction between the organ and the main plant [14] [15]. These cells are supposedly predetermined at an early age [16]. For a brief period of time before abscission, these cells are able to respond to chemical signals that trigger abscission. The cells in the AZ enlarge prior to abscission. During abscission the mid- 
dle lamella of the cell wall is dissolved by wall degrading enzymes, such as cellulase and pectinase, which forms a fracture plane. These diverse hydrolytic enzymes orchestrate abscission and seal the AZ cell walls on the remaining part of the plant [17] [18]. AZ was recently identified in balsam fir and was speculated to function in a similar manner [19], where prolonged exposure to ethylene activates the hydrolytic enzyme cellulase, which weakens the cell walls and causes abscission [5].

Abscission, in general, is regulated by environmental as well as developmental cues. For example, cold acclimation increases abscisic acid (ABA) and certain sugars in conifers, which tends to delay postharvest needle abscission [20]. It has been shown that cold acclimation is triggered through environmental signals of both decreasing temperature and photoperiod [21]. The cells of the AZ are able to respond to certain signals and abscission may be activated in times of stress mediated by hormones. To date, the only hormone conclusively found to induce abscission in balsam fir is ethylene [22]. Ethylene evolution is increased prior to abscission and abscission is delayed with the application of ethylene inhibitors, such as aminoethoxyvinylglycine or 1-methylcyclopropene [5] [22]. Other growth regulators that may be related to abscission are ABA, abscisic acid; AUX, auxins; JA, jasmonic acid; PA, polyamines; BR, brassinosteroids; cytokinins; and GA, gibberellins [6]. Signals from hormones potentially lead to the activation of genes promoting AZ separation, but FA and lipids may also be involved either before or after hormone production [13] [23], but the information is lacking. The complete mechanisms that regulate abscission and the potential role of FA signaling remains largely unknown.

\section{Types of Lipids}

In plants, there are 3 main classes of membrane lipids; glycerolipids, sphingolipids, and sterols [24] [25]. Glycerolipids consist of 4 main groups: galactolipids (GL), phospholipids (PL), triacylglycerols; and sulfolipids (SL) [24]. In leaves, the glycerolipids studied in relation to membrane damage are primarily GL and $\mathrm{PL}$, thus are the focus of this review. It should be noted however that knowledge is increasing in the area of cuticular lipids and sphingolipids and their role in adaptation to stress, but they are not included in this review [26]. GL, are associated mostly with the chloroplast membranes, and PL is a constituent of other membranes of the cell, particularly the plasma membrane [8] [27].

Lipid nomenclature has been reviewed and universally accepted in 2005, updated once more in 2009, to meet the growing field of lipidomics [25]. To understand glycerolipid composition and their role in the signaling processes, there have been notable changes to the naming and abbreviating of lipid classes and species, of which, there are 3009 categories listed in the LIPID MAPS database [25]. This review will be using the updated names and abbreviations.

\subsection{Galactolipids}

Monogalactosyldiacylglycerol (MGDG) and digalactosyldiacylglycerol (DGDG) 
(Figure 1) are both GLs found in the chloroplast membranes, are the most abundant glycerolipids in leaves, and major sources of PUFA [8] [28]. These lipids have one or two galactosyl head groups, and contain no phosphate [24] [29]. MGDG is abundant in the thylakoids and the inner chloroplast membrane, whereas DGDG is more abundant in the outer membrane. MGDG is confined to the chloroplast, whereas DGDG is sometimes found in the plasma membrane, and tends to replace PL in times of phosphate starvation [30]. GL are speculated to be important for photosynthesis, and often they are one of the first organelles to be damaged in times of stress resulting in photoinactivation [31]. Chloroplast remodeling of MGDG and DGD occurs in stressful situation such as water deprivation [31] [32].

\subsection{Phospholipids}

PL are synthesized by esterification of FA to two hydroxyl groups of sn-glycerol3 phosphate to produce phosphatidic acid (PA). All other PL are created by esterification of various head groups. FA are attached to the sterospecific or sn-1 and 2 positions (Figure 2). The following plant structural PL classes are presented in

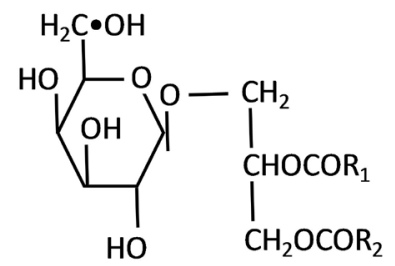

Monogalactosyldiacylglycerol (MGMG)

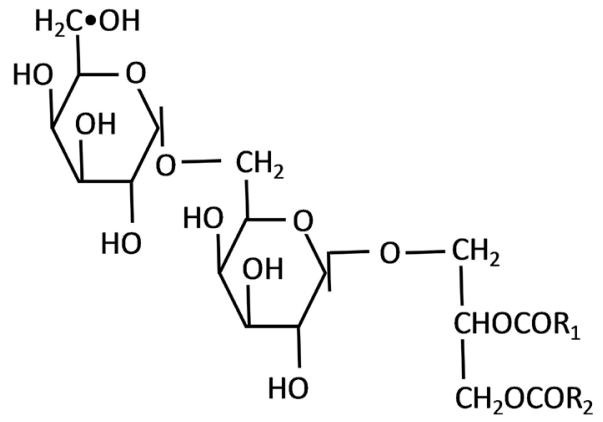

Digalactosyldiacylglycerol (DGMG)

Figure 1. Structure, of the common galactolipids, MGDG and DGDG, R = fatty acid [60].

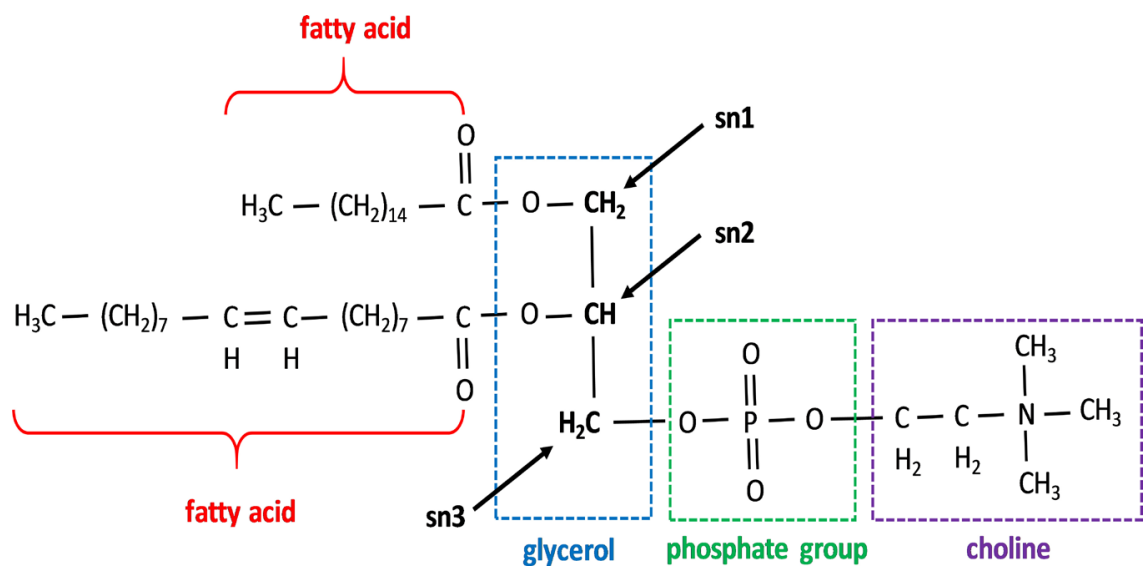

Figure 2. Phospholipids showing phosphatidylcholine structure. All phospholipids have the same basic structure with different head groups instead of choline and varied fatty acids. Sn 1, 2, and 3 positions are marked [102]. 
their order of abundance: 1) PC, phosphatidylcholine, 2) PE, phoshatidylethanolamine, 3) PG, phosphatidylglycerol, and 4) PS, phosphatidylserine [33]. Signaling PL have been identified as, 1) PA, 2) DGPP, diacylglycerolpyrrophosphate, 3) lysoPA, lysophophatidic acid, and 4) PI, phosphoinositol, including phosphoinositol polyphosphates (phosphorylated derivatives of PI). Phosphorylated derivatives of PI are named according to number and position of phosphate groups, such as PIP, phosphatidylinositol monophosphate, $\mathrm{PIP}_{2}$, phosphatidylinositol bisphosphate, and $\mathrm{IP}_{3}$, inositol triphosphate [33] [34] [35] [36]. Classes are determined by the head group of the PL, but species are determined by the FA composing the tails of the particular class of PL. The composition of the tail groups is specific to various organelles and thought to be related to function [37] [38].

\section{Fatty Acids}

Plant cells typically contain $5 \%-10 \%$ lipids, primarily in the cellular membranes, with $40 \%-50 \%$ of these found in the chloroplast [39]. Lipids are FA and their derivatives, FA being organic compounds synthesized by the condensation of malonyl coenzyme-A units by FA synthase in the plastids. FA make up the acyl chains or "tails" of all glycerolipids, and are either saturated or unsaturated, having no double bonds or at least one double bond, respectively. FA are dynamic molecules, can vary in the degree of unsaturation, and saturated FA can become unsaturated through the action of desaturase enzymes controlled by fatty acid desaturase genes [40]. If FA contain more than one double bond, they are called polyunsaturated FA (PUFA). Those with one double bond are monounsaturated fatty acids (MUFA). Five FA make up over $90 \%$ of the acyl chains in plant glycerolipids: 18:1n9, oleic acid; 18:2n6; linoleic acid; 18:3n3, $\alpha$-linolenic acid; 16:0, palmitic; 16:3n3, hexadecatrienoic acid [40]. Free FAs are found in very small amounts in plant cells, but can be hydrolyzed from lipids in all membranes [39].

FA structure is known to change with varying environmental conditions, and composition is important in determining the ability of plants to respond to stresses [24] [41]. Under certain conditions, such as cold temperature, the majority of all FA are made up of PUFA, 18:3n3 [24]. A shift towards unsaturated FAs is thought to help maintain membrane fluidity and lower the required temperature for membrane phase changes [42]. Consistent shifts in FAs in response to cold were reported in many different conifer species [43].

\section{Fatty Acid and Lipid Synthesis}

FA are necessary for production of cellular lipids. FA synthesis starts with Acetyl Co-enzyme A (Acetyl Co-A), a product of the citric acid cycle. It is the direct precursor for the methyl end of the FA. Synthesis starts with the carboxylation of acetyl Co-A into malonyl Co-A utilizing acetyl Co-A carboxylase. Malonyl Co-A is, in turn, acted on to produce saturated fatty acids palmitate and stearate, the 
latter being more common in plants. These saturated FA can be further elongated and desaturated to form specific mono- and polyunsaturated FA (Figure 3).

Lipids are synthesized in the chloroplast and the endoplasmic reticulum (ER), via prokaryotic and eukaryotic pathways, respectively [31] [44]. The prokaryotic pathway results in 16-C FA in the sn-2 position, whereas the prokaryotic pathway results in a lipid containing an 18-carbon FA in the sn-2 position. It is not known which pathway the balsam fir uses. However, in all cells, lipid trafficking is required to distribute lipids to all parts of the cell, including the cuticle. A disruption in any or all functional membranes can interfere with synthesis and distribution of lipids [31] [45]. Maintaining healthy chloroplast membranes is important for balsam fir postharvest for both photosynthesis and lipid synthesis [31]. Lipid synthesis begins in the chloroplast-firstly incorporating FA into galactolipids, MGDG and DGDG, and PG, the main PL in the thylakoid and inner chloroplast membrane. The FA in the sn-2 position varies depending on the pathway utilized. In addition to chloroplast lipid biosynthesis, there is a huge flux of FA to the endoplasmic reticulum for processing into other PL, which in turn are transported to the plasma membrane and other intracellular organelle membranes.

\section{Physiological Changes Occurring during Abscission in Balsam Firpostharvest}

Many biophysical and hormonal changes have been monitored in postharvest balsam fir [6]. There was a decrease in postharvest water usage, xylem pressure potential, relative water content, capacitance, needle break strength, chlorophyll index, andidoleacetic acid (IAA). On the other hand, there was an increase in needle loss, membrane injury index (MII), ABA, and CKs. Decreases in water use, xylem pressure potential, relative water content, and capacitance combined with increases in MII and ABA are consistent with water deficit stress and dehydration [6]. Decrease in IAA is related to increasing sensitivity to ethylene,

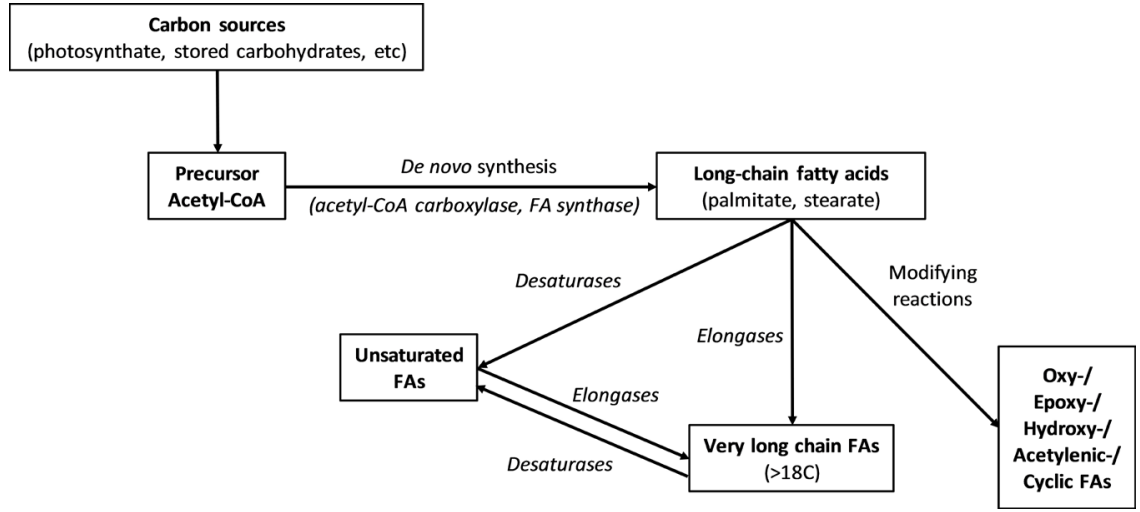

Figure 3. Summary of fatty acid synthesis resulting in unsaturated, saturated and unusual fatty acids. 
whereas the decrease in break strength is linked to cell wall breakdown and abscission [22] [46]. Prior research has identified prolonged exposure to ethylene as a mediator of abscission in balsam fir postharvest [47], while [6] additionally suggest key roles for $\mathrm{ABA}$, IAA, and $\mathrm{CK}$, in postharvest needle abscission.

Another biophysical change of great interest is needle retention related to clonal variations and cold acclimation. Cold acclimation data is important to Christmas tree producers in planning their harvest date. In addition, trees are being harvested earlier to meet export demands, which results in poorer needle retention postharvest. There are significant differences between in needle retention duration (NRD) between balsam fir genotypes. Low NRD genotypes would abscise needles in less than 20 days while high NRD genotypes would not abscise needles until after 40 days [20]. It was found high needle retaining genotypes changed very little from September to January in needle retention, whereas low needle retaining genotypes had increased needle retenton [20]. Many studies have been published on cold acclimation for other plant species, and it has been shown that lipid and FA composition has a great impact on the ability to survive at cold temperatures [48] [49] [50]. The degree of unsaturation of the needles also could be related to needle retention postharvest in balsam fir.

\section{Roles of Glycerolipids and Fatty Acids in Stress Responses}

GL and PL play essential roles as mitigators of stress. As stated previously, membrane integrity is important to the survival of the cell. Membranes are very dynamic, and can change due to external cues such as abiotic stresses. In addition, they can be reservoirs for biologically active lipids [51]. Photosynthetic membranes are particularly sensitive to environmental cues, and have a high degree of plasticity to prevent photoinactivation, which can lead to cell damage [24]. Reactive oxygen species (ROS), such as $\mathrm{H}_{2} \mathrm{O}_{2},{ }^{\circ} \mathrm{OH}$, and $\mathrm{O}_{2}{ }^{-}$, are now thought to be the primary cause of cell damage during stress, and could be related to balsam fir needle abscission and/or senescence postharvest [52]. Normal aerobic processes in the cell generate ROS, via the enzyme NADPH oxidase, nicotinamide adenine dinucleotide phosphate-oxidase oxidase, whereas antioxidant defense systems scavenge ROS and maintain them at non-damaging levels [53] [54]. Successful activation of antioxidant enzymes, such as catalase or superoxide dismutase (SOD), will produce enough antioxidants to keep ROS in check. However, there can be an oxidative burst caused by abundance of respiratory burst homologs, NADP oxidases, related to a change to beta oxidation in the cell during stress [54]. This upsets the delicate ROS/antioxidant balance creating oxidative stress, resulting in lipid degradation, and damaging the cellular membranes [55]. This is linked to loss of membrane integrity, which has been found to correlate with abscission in and senescence in balsam postharvest [6]. It is possible that certain clones of balsam fir postharvest can more efficiently scavenge ROS due to their membrane FA composition and structure than others.

FAs are critical in preventing damage by ROS, thus preventing membrane leakage leading to cell senescence, and possibly abscission. As previously stated, 
FAs determine the species of each lipid class. For example, lipid species are as follows with the fatty acids composing them in brackets: 34:2 (16:0 - 18:2), 34:3 (16:0 - 18:3), 36:4 (18:2 - 18:2), 36:5 (18:2 - 18:3), and 36:6 (18:3 - 18:3). These are the most common arrangement found in GL and PL [56]. Increased fluidity of membranes is related to increased desaturation of membrane lipids, and often a desaturase enzyme will be activated in times of stress to preserve fluidity [57].

One of the best-known examples of compositional changes in FA and lipids is the unsaturation of glycerolipid. Increases of unsaturated FA in cellular membranes, both at the beginning and along the acclimation period are important for increased cold sensitivity [50]. This maintains proper membrane fluidity, stability of the chloroplast membranes, and ROS scavenging ability. There is an increase in unsaturated versus saturated FA during cold acclimation. It is thought that CKs may play a role in increasing membrane desaturation and the ability to deal with drought stress [58] [59].

It is also thought that CK triggers more DGDG production, decreasing the MGDG: DGDG ratio in the cell. Under non-stressful conditions, MGDG makes up $50 \%$ of chloroplast membrane lipids, as opposed to $20 \%$ by DGDG. MGDG form a single layer of lipids which are important efficiency of the thylakoid membranes. DGDG form a bilayer and can create greater stability for the chloroplast during stress. MGDG is converted into DGDG during low temperature stress or drought stress, which results in more bilayer lipids in the chloroplast providing greater stability [58] [60].

The fact that $\mathrm{CK}$ is thought to trigger these adaptations during stress does not explain the doubling of CK seen during abscission in balsam fir [6]. This finding in balsam fir contradicts previous studies in which CK are thought to be able to negate the effects of water stress since they are thought to be antagonistic to ABA [61]. However, various CKs may have varying effects on the cell, and sometimes exogenous applications, used in most studies, may produce a different result than endogenous formation CKs have been found to have hierarchal distribution and local effect in other conifer species with terminal parts of a branch having twice as much as lateral parts of a branch [62].

Cold acclimation changes in other plants can possibly shed light on clonal differences previously mentioned in postharvest balsam fir in high and low NRD clones. Prior to cold acclimation, high NRD clones may have more unsaturated FA in their membranes than low NRD clones, making them a better choice for earlier harvest. Their membranes are more fluid and they can effectively scavenge ROS for longer. In addition, these high NRD clones, if indeed this is true, would have an abundance of precursor molecules for jasmonic acid (JA) production, which is known to enhance stress tolerance [63] [64]. If stress prolongs, lipid biosynthesis may not be able to keep up with replacing the degraded membrane lipids or the products of lipid degradation or ROS may become cytotoxic, and finally the branches succumb to the stress by abscising needles. High NRD clones may not change much during cold acclimation, whereas low NRD clones could last longer after acclimation due to greater desaturation of their mem- 
brane lipids than previously, now having the benefits that the high NRD clones had earlier in the season. If this is so, there should be a greater increase in unsaturation before and after cold acclimation in low NRD clones than in high NRD clones. In low NRD clones, it is possible that the presence of fewer unsaturated FA in the lipid bilayer may be present than in high NRD clones before cold acclimation occurs. This may affect membrane integrity postharvest for trees harvested at that time. As cold acclimation occurs, the low NRD clones may undergo more desaturation than the high NRD clones, stabilizing the membranes of the low NRD clones and resulting in better needle retention postharvest. From previous studies, there is better membrane integrity in high NRD clones before cold acclimation, or as speculated in Lada and MacDonald 2015, perhaps high NRD clones have greater temperature sensitivity and start the cold acclimation process earlier.

\subsection{Signal Transduction and Phospholipases}

Plasma membrane lipids are the first to receive environmental stimuli or stimuli from a neighboring cell [65] [66]. Hormones react with receptors on the surface of the cell, initiating a signaling cascade, often referred to as a signal transduction pathway that will produce precursor lipids, their effector enzymes, as well as the resulting breakdown products [24] [37] [67]. These messengers stimulate a response or amplify the signal to help increase stress tolerance, or help the plant adapt to their new environment. Signaling involves interactions and crosstalk between lipids and phytohormones, $\mathrm{ROS}, \mathrm{Ca}^{2+}$, enzymes, and transcription factors [12] [68]. When a fir tree is cut, it initially responds to wounding stress and later on to dehydration stress. These two stimuli may bring about different responses, and in addition responses will vary due to the speed of imposition, degree of stress, and interaction with other chemicals [69] [70] [71]. Inherently, there will be responses at the cellular level related to survival, which may inhibit growth, initiate abscission of some plant parts to preserve the rest, or result in cell death [71].

Lipid signaling pathways are complex, interrelated, and involve numerous enzymes. Phospholipases are key ubiquitous enzymes related to stress response, and lipid and FA signaling [72]. Three main types of this enzyme classes cleave PL in different locations. The major phospholipases are PLA, phospholipase A, PLC, and PLD. PLA hydrolyzes membrane PL into corresponding lysoPLs, such as lysoPC, and FFA [73]. These FA can act as precursors for oxylipin biosynthesis, or FA can be signaling molecules in their own right. For instance, oleic acid has been known to stimulate phospholipase enzymes that cleave PL during stress. The second messengers, lysoPLs, can activate H-ATPase in the tonoplast, causing acidification of the cytoplasm, a known stress response. PLC activates the $\mathrm{IP}_{3}$ pathway, and collaborates with another enzyme, DGK, diglycerol kinase, to activate the DAG, diacylglycerol, pathway. DAG is further transformed into another second messenger, PA. PLD hydrolyzes PL resulting directly in the formation of PA via a different pathway [74] [75]. There is very little research done 
on gymnosperm lipid signaling, but due to the ubiquitous nature of these phospholipases, it is likely they are involved in balsam fir signaling abscission postharvest.

\subsection{Inositol Polyphosphates and Signaling}

PI and its many phosphorylated isomers have the ability to permeate both hydrophobic and hydrophilic environments, making them perfect signaling molecules [45]. The $\mathrm{IP}_{3}$ and DAG signal transduction pathways are most well-known pathways in plants. A transient increase in $\mathrm{PIP}_{2}$, the initiator of this pathway in the cell membrane in response to stress has been well documented [24]. $\mathrm{PIP}_{2}$ is the precursor molecule for both $\mathrm{IP}_{3}$ and DAG, which are both secondary messengers in the cell. A signaling molecule, potentially a hormone, binds to the receptor in the plasma membrane. These receptors have a wide array of ligands and are associated with $g$-proteins. An activated $g$-protein in turn activates PLC. PLC cleaves PIP $_{2}$, which is in the plasma membrane, into $\mathrm{IP}_{3}$ and DAG. After this cleavage, two distinct downstream pathways are activated, referred to as the $\mathrm{IP}_{3}$ pathway and the DAG pathway [24]. $\mathrm{IP}_{3}$ binds to receptors on the endoplasmic reticulum (ER) of the cell and mobilizes $\mathrm{Ca}^{2+}$, calcium, from the ER into the cytosol. $\mathrm{Ca}^{2+}$ is also considered a second messenger. $\mathrm{IP}_{3}$ has been implicated in ABA expression and stomatal closure, which we know occurs in balsam fir postharvest [65] [76].

\subsection{PA and Signaling}

PA is emerging as a very versatile second messenger in the cell [38] [75] [77]. PA is a stress signaling molecule in plants playing a role in degradation, signaling, and lipid turnover. PA is produced via 1) de novo PL bio-acylation of lysoPA, 2) PLD hydrolysis of PL, and 3) the DAKP pathway mentioned in the last section. Using the DAKP pathway, PIP $_{2}$ is a critical cofactor for PLD, and profoundly affects the activity of PLD [78]. There have been many links made between PA and/or its catalyzing enzymes to biophysical and phytohormonal changes in the cell [34]. PLD and PA are linked to wounding and drought stresses, the two identified stresses that balsam fir have to deal with postharvest. However, no work on PA signalling has been conducted in balsam fir or related conifers.

\subsection{Oxylipins and Signaling}

Oxylipins are oxidized lipids, the most commonly known oxylipin being JA. JA is rapidly emerging as an important lipid-based signaling molecule in plants, related to many stress responses [71] [79]. JA synthesis originates from PUFA, $18: 3 \mathrm{n} 3$ and $16: 3 \mathrm{n} 3$, primarily found in the chloroplast membranes, repl enished as needed. When stress is detected in the cell, these FA are converted into 13-hydroperoxylinolenic acid by LOX, lipoxygenase. This, in turn, is a substrate for allene oxide synthase and allene oxide cyclase resulting in the formation of 12-oxo-phytodienoic acid. JA is formed after reduction and three steps of oxida- 
tion. JA can be catabolized to form MeJA, methyl jasmonate, and numerous conjugates and metabolites [66] [79].

JA induces or promotes ethylene synthesis in many species postharvest [33] [80] [81]. In Zea mays, induced JA levels resulted in maximal ethylene levels 8 16 hours later [82]. In addition, JA and ethylene were found to work together to elicit a stress response in tobacco plants [83]. JA promoted ethylene in several conifers as well, though studies tend to focus on the role of JA in conifer defense [84]. The role of JA in balsam fir specifically has never been studied, though it was speculated that JA should be involved due to the mechanical wounding of harvested trees and changes in volatile terpenes [10].

\subsection{Possible Interactions between Signaling Molecules and Other Cell Molecules}

There is a multitude of findings about signaling lipids, $\mathrm{ROS}, \mathrm{Ca}^{2+}$, and phytohormones and their role during stress, but not many researchers look at all the components in one study. Consistently, ethylene and ABA have been identified as phytohormones related to abscission in balsam fir postharvest, as well as other plants [6] [22] [85] [86]. A low concentration of ethylene has been found to delay abscission, whereas a high concentration induces abscission [47]. Interestingly, the same relationship exists between $\mathrm{ABA}$ and abscission, suggesting a linkage between the two [76]. These results concur with research by [62] on abscission and senescence in poplar trees. In both, ABA delayed abscission in drought resistant genotypes, and promoted abscission in drought sensitive types, which emphasized clonal variationsin balsam fir postharvest. Possible interactions between signaling molecules are described below and all presented in Figure 4.

PA has been implicated in signaling pathways related to ABA and ethylene, and can be suggested as a potential link between the two [63] [71]. ABA stimulates PLD $\alpha 1$, which in turn stimulates PA production from PL, and subsequently leads to endogenous ethylene production, making a connection between ABA, $\mathrm{PA}$, and ethylene production [87] [88]. In addition, an increase in ABA in water-stressed plants promoted synthesis of the precursor for ethylene, ACC, 1-amino cyclopropane-1-carboxylic acid [88]. With regards to senescence, independent action of ABA and ethylene has been suggested [89], but the relationship between these two hormones leading up to abscission in balsam fir postharvest is unknown. We do know they both increase in concentration postharvest in balsam fir. ABA might hold an upstream pathway and synergistic role with ethylene to induce abscission in root-detached balsam fir [76]. PA then may hold a regulatory role in synthesis or effect of ABA [90].

Recent studies have shown that drought related stress responses are mediated by ROS, in particular $\mathrm{H}_{2} \mathrm{O}_{2}$ [91] [92]. Protein kinase $\mathrm{C}$ activated by $\mathrm{Ca}^{2+}$ and DAG facilitates assembly and activation of NADPH oxidase on the outer membrane, which generates ROS [55]. ROS resulted in a burst of ethylene with a subsequent decrease in catalase, SOD, and ROS scavengers [93]. It has also been 


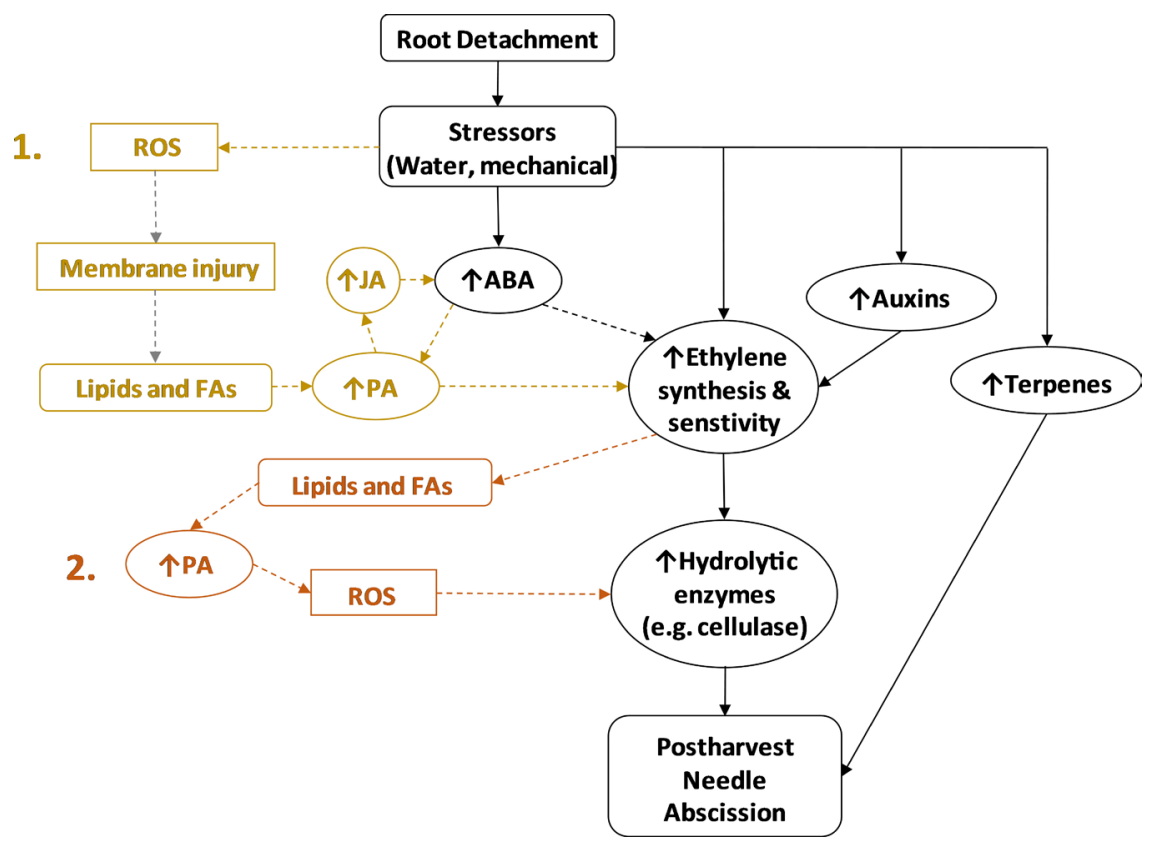

Figure 4. Schematic for proposed pathways from root detachment to abscission in balsam fir. Connections in black are established parts of the pathways, while those not in black represent unknown linkages in balsam fir that make sense based on studies in other species. Specifically, connections in yellow represent the possible upstream role of lipids and ROS, while orange represents the possible downstream role. ABA: abscisic acid; FA: fatty acid; JA: jasmonic acid; PA: phosphatidic acid; ROS: reactive oxygen species.

shown that PLD $\alpha 1$ and PA are involved in ROS production. Depletion of PLD $\alpha 1$ in Arabidopsis lessens the ROS production, while the addition of PA restores ROS production [94]. One possibility is that ROS stimulates ABA synthesis, placing ROS upstream of ABA [90]. A second possibility is that an increase in ABA stimulates the production of ROS, particularly $\mathrm{H}_{2} \mathrm{O}_{2}$, which then works as an intermediate necessary for ABA's mode of action [94]. If ROS are triggered via $A B A$, this would place ROS downstream from $A B A$. In addition, there is a demonstrated relationship between ROS, $\mathrm{ABA}$, and ethylene during drought stress [70]. If this is the case, $\mathrm{IP}_{3}$ could be a lipid second messenger as well in this scenario. ABA regulates stomatal closure, which occurs upon activation of drought sensors in the outer plasma membrane. One key component in this mechanism is an initial increase in cytosolic $\mathrm{Ca}^{2+}$ concentrations that occurs within minutes of ABA exposure in Arabidopsis [85] [86]. This rapid increase in $\mathrm{Ca}^{2+}$ is preceded by an increase in $\mathrm{IP}_{3}$ and is dependent on increased PLC activity [1] [94]. ABA could be the hormone that starts the $\mathrm{IP}_{3}$ and DAG pathways since ABA induced PI turnover in guard cells [1].

Alternate studies have named ethylene as the mediator of PLD synthesis, further confirming that there is more than one pathway. In glucose-starved carrots ethylene mediated a PLD catabolic pathway leading to PA production [1]. Other sources say that ethylene up regulates the PLD $\alpha$ gene [95]. These studies place PA downstream of ethylene, with PA still affected ROS production. A study by 
[96] has proposed the pathway for petiole abscission in detached Capsicum leaves, and has placed $\mathrm{H}_{2} \mathrm{O}_{2}$ downstream of ethylene. Unfortunately, PLD, PA, and $\mathrm{ABA}$ were not included in this study. The Capsicum leaves were root-detached and hydrated and placed in an in vitro system to study stress-induced abscission in the abscission zone under various conditions. Firstly, similar to what has been observed in balsam fir during postharvest abscission, IAA was depleted, and the addition of IAA inhibited abscission. Low levels of IAA have been linked to greater ethylene sensitivity and more sensitivity to $\mathrm{H}_{2} \mathrm{O}_{2}$, thus mitigating stress [97] [98] [99]. Abscission was found to be induced by ethylene in Capsicum leaves, as we know happens in balsam fir postharvest. However, a continuous production of $\mathrm{H}_{2} \mathrm{O}_{2}$ by $\mathrm{AZ}$ cells was also recorded under stressful conditions prior to abscission, and this was related to cellulase production, an enzyme known to be involved in cell wall breakdown in plants, including balsam fir postharvest [5] [16]. Abscission was inhibited by addition of catalase, a ROS scavenging enzyme, making a direct connection between ROS and abscission. $\mathrm{H}_{2} \mathrm{O}_{2}$ inhibitors reduced abscission in the presence of ethylene stimulants, proving that $\mathrm{H}_{2} \mathrm{O}_{2}$ was working downstream of ethylene in Capsicum, and in turn up regulates the expression of cellulase genes. If this is the case, ethylene could stimulate the activity of PLD to produce PA, which in turn caused the production of $\mathrm{H}_{2} \mathrm{O}_{2}$ and cellulase production-and ultimately abscission. Hormonal changes in balsam fir were very similar to those in detached Capsicum leaves, which suggests that ROS may play a similar role in downstream regulation from ethylene.

Conflicting reports as to the role and identity of PLD and PA suggests multiple PLD and PA pathways and responses in plants. Plants have 12 genes controlling 12 different PLD species compared to animals that have only 2, so there should many more biochemical pathways involving these isomers in plants than animals [100]. The PLD isomers shown in Figure 5 show different pathways: one involving the $\mathrm{ABA}$ response, a second involving the ROS response, and a third involving nutrient sensing. If this is so, could there be some crosstalk between two pathways. Notice that in Figure 5 PLD $\alpha 1$ stimulates PA and then ABA. Further research about PLD shows that there is an increase in PLD $\alpha$ and, subsequently, PA prior to JA production as well. It is thought that PA begins MAPK, mitogen-activated protein kinase, signaling into the nucleus affecting gene expression of CYP94B1 which is involved in JA-Ile turnover and attenuation of JA responses [101]. JA is known to increase one hundred folds when a plant is under stress. JA is also thought to be involved in stomatal closure during drought stress. Recently, researchers have gone so far to say that a burst of JA is needed for production of ABA [80]. In postharvest balsam fir, JA has not been tested, but this phytohormone is associated with wounding, which occurs when the tree is cut. ABA increases after the initial wounding [6] [10], but more research is needed in postharvest balsam fir to determine how quickly it accumulates and the relationship it has to JA. 


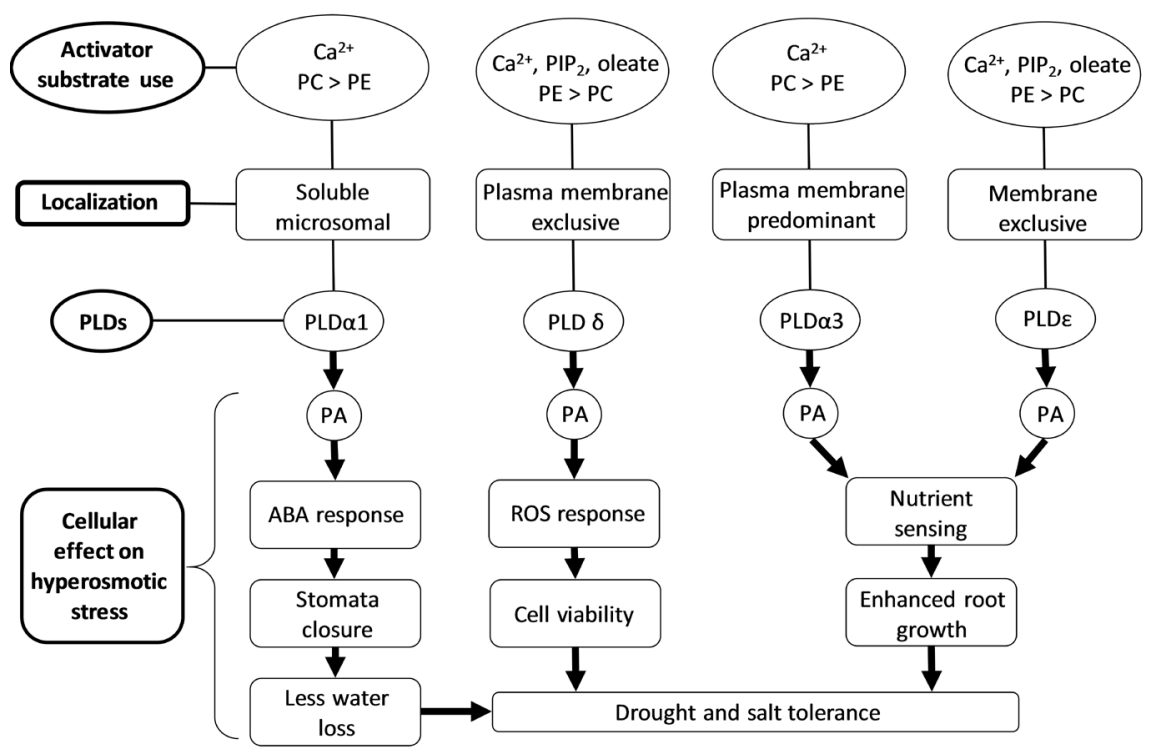

Figure 5. Multiple pathways for carious PLD enzymes that occur during drought stress and other stresses in plants [103]. ABA: abscisic acid; PA: phosphatidic acid; PC: phosphatidylcholine; PE: phoshatidylethanolamine; $\mathrm{PIP}_{2}$ : phosphatidylinositol bisphosphate; PLD: phospholipase D; ROS: reactive oxygen species.

\section{Conclusion}

In this review various reports and papers describing the roles of plant lipids as mitigators of stress and as signaling molecules have been reported. Studies increasingly indicate that FA and glycerolipids crosstalk with phytohormones, enzymes, $\mathrm{Ca}^{2+}$, and ROS to achieve responses to water deficits and other stresses that occur when a tree is detached from its roots, even when water is provided, as in the case of a Christmas tree. In addition, cellular membranes are also the target of damage leading to membrane leakage in most of these reports, and decrease in membrane integrity has been associated with senescence and abscission in postharvest balsam fir. The model proposed in this review highlights the potential role for lipids and FAs both upstream and downstream from increased $\mathrm{ABA}$ and ethylene evolution associated with abscission. Understanding the dynamics of change in lipids and fatty acids in the needle of balsam fir postharvest, the role of cold acclimation on the lipids and fatty acids, and to validate whether the clonal differences in the needle abscission resistance can be explained in terms of changes in lipid and fatty acids is necessary. Key steps in establishing the true role(s) of lipids in postharvest abscission will to identify whether changes in lipid composition occur prior to an increase in ethylene, whether application of ethylene inhibitors also negate certain changes in lipid composition, and to understand lipid profile differences between high and low NRD genotypes. Identification of signaling molecules has the potential to connect the stimulus perception at the cell membrane to intracellular actions and physiological responses to stress in balsam fir postharvest and allow us to build on this knowledge to develop new technologies to protect membranes and increase resistance 
to needle abscission in root-detached balsam fir and other conifers.

\section{Conflicts of Interest}

The authors declare no conflicts of interest regarding the publication of this article.

\section{References}

[1] Lee, Y., Choi, Y., Suh, S., Lee, J., Assmann, S., Joe, C., Kelleher, J. and Crain, R. (1996) Abscisic Acid-Induced Phosphoinositide Turnover in Guard Cell Protoplasts of Vicia faba. Plant Physiology, 110, 987-996. https://doi.org/10.1104/pp.110.3.987

[2] Rawyler, A., Asparagus, S. and Braendle, R. (2002) Impact of Oxygen Stress and Energy Availability on Membrane Stability of Plant Cells. Annals of Botany, 90, 499-507. https://doi.org/10.1093/aob/mcf126

[3] Testerink, C. and Munnik, T. (2005) Phosphatidic Acid: A Multifunctional Stress Signaling Lipid in Plants. Trends in Plant Science, 10, 368-375. https://doi.org/10.1016/j.tplants.2005.06.002

[4] Sharkey, T. (1997) The Physiology of Plants under Stress: Abiotic Factors. In: Nilsen, E. and Orcutt, D., Eds., The Quarterly Review of Biology, The University of Chicago Press, Chicago, IL, 476-477. https://doi.org/10.1086/419999

[5] MacDonald, M.T., Lada, R.R., Dorais, M. and Pepin, S. (2011) Endogenous and Exogenous Ethylene Induces Needle Abscission and Cellulase Activity in Post-Harvest Balsam Fir (Abies balsamea L.). Trees, 25, 947-952. https://doi.org/10.1007/s00468-011-0569-3

[6] MacDonald, M.T. and Lada, R.R. (2014) Biophysical and Hormonal Changes Linked to Postharvest Needle Abscission in Balsam Fir. Journal of Plant Growth Regulation, 33, 602-611. https://doi.org/10.1007/s00344-013-9409-6

[7] Lessire, R., Cahoon, E., Chapman, K., Dyer, J., Eastmond, P. and Heinz, E. (2009) Highlights of Recent Progress in Plant Lipid Research. Plant Physiology and Biochemistry, 47, 443-447. https://doi.org/10.1016/j.plaphy.2009.02.010

[8] Dörmann, P. and Benning, C. (2002) Galactolipids Rule in Seed Plants. Trends in Plant Science, 7, 112-118. https://doi.org/10.1016/S1360-1385(01)02216-6

[9] Zhao, Y., Qian, C., Chen, J., Peng, Y. and Mao, L. (2010) Responses of Phospholipase $\mathrm{D}$ and Lipoxygenase to Mechanical Wounding in Postharvest Cucumber Fruits. Journal of Zhejiang University SCIENCE B, 11, 443-450. https://doi.org/10.1631/jzus.B0900357

[10] Lada, R.R. and MacDonald, M.T. (2015) Understanding the Physiology of Postharvest Needle Abscission in Balsam Fir. Frontiers in Plant Science, 6, 1069. https://doi.org/10.3389/fpls.2015.01069

[11] Lada, R.R. and MacDonald, M.T. (2016) Differences in Dehydration Rate and Ability to Rehydrate in Contrasting Needle Abscission Resistant Balsam Fir Genotypes. Scientia Horticulturae, 211, 391-398. https://doi.org/10.1016/j.scienta.2016.09.021

[12] Lewis, M.W., Leslie, M.E. and Liljegren, S.J. (2006) Plant Separation: 50 Ways to Leave Your Mother. Current Opinion in Plant Biology, 9, 59-65. https://doi.org/10.1016/j.pbi.2005.11.009

[13] Estornell, L.H., Agustí, J., Merelo, P., Talón, M. and Tadeo, F.R. (2013) Elucidating Mechanisms Underlying Organ Abscission. Plant Science, 199-200, 48-60. https://doi.org/10.1016/j.plantsci.2012.10.008 
[14] Sexton, R. and Roberts, J.A. (1982) Cell Biology of Abscission. Annual Review of Plant Physiology, 33, 133-162. https://doi.org/10.1146/annurev.pp.33.060182.001025

[15] Taylor, J.E. and Whitelaw, C.A. (2001) Signals in Abscission. New Phytologist, 151, 323-340. https://doi.org/10.1046/j.0028-646x.2001.00194.x

[16] Patterson, S.E. (2001) Cutting Loose. Abscission and Dehiscence in Arabidopsis. Plant Physiology, 126, 494-500. https://doi.org/10.1104/pp.126.2.494

[17] Addicott, T.F. (1982) Abscission. University of California Press, Oakland, CA.

[18] Liljegren, S.J. (2012) Organ Abscission: Exit Strategies Require Signals and Moving Traffic. Current Opinion in Plant Biology, 15, 670-676. https://doi.org/10.1016/j.pbi.2012.09.012

[19] Thiagarajan, A., MacDonald, M.T. and Lada, R. (2016) Environmental and Hormonal Physiology of Postharvest Needle Abscission in Christmas Trees. Critical Reviews in Plant Sciences, 35, 1-17. https://doi.org/10.1080/07352689.2015.1133965

[20] MacDonald, M.T., Lada, R.R., Veitch, R.S., Thiagarajan, A. and Adams, A.D. (2014) Postharvest Needle Abscission Resistance of Balsam Fir ( Abies balsamea) Is Modified by Harvest Date. Canadian Journal of Forest Research, 44, 1394-1401. https://doi.org/10.1139/cjfr-2014-0199

[21] MacDonald, M.T., Lada, R.R. and Veitch, R.S. (2017) Seasonal Changes in Balsam Fir Needle Abscission Patterns and Links to Environmental Factors. Scandinavian Journal of Forest Research, 32, 438-445. https://doi.org/10.1080/02827581.2016.1235726

[22] MacDonald, M.T., Lada, R.R., Martynenko, A.I., Dorais, M., Pepin, S. and Desjardins, Y. (2010) Ethylene Triggers Needle Abscission in Root-Detached Balsam Fir. Trees, 24, 879-886. https://doi.org/10.1007/s00468-010-0457-2

[23] Kubigsteltig, I., Laudert, D. and Weiler, E.W. (1999) Structure and Regulation of the Arabidopsis thaliana Allene Oxide Synthase Gene. Planta, 208, 463-471. https://doi.org/10.1007/s004250050583

[24] Buchanan, B., Gruissem, W. and Jones, L. (2000) Lipids. Springer, India.

[25] Fahy, E., Subramaniam, S., Murphy, R.C., Nishijima, M., Raetz, C.R.H., Shimizu, T., Spener, F., van Meer, G., Wakelam, M.J.O. and Dennis, E.A. (2009) Update of the LIPID MAPS Comprehensive Classification System for Lipids. Journal of Lipid Research, 50, S9-S14. https://doi.org/10.1194/jlr.R800095-JLR200

[26] Worrall, D., Ng, C.K.-Y. and Hetherington, A.M. (2003) Sphingolipids, New Players in Plant Signaling. Trends in Plant Science, 8, 317-320. https://doi.org/10.1016/S1360-1385(03)00128-6

[27] Lee, A.G. (2000) Membrane Lipids: It's Only a Phase. Current Biology, 10, 377-380. https://doi.org/10.1016/S0960-9822(00)00477-2

[28] Kaniuga, Z. (2008) Chilling Response of Plants: Importance of Galactolipase, Free Fatty Acids and Free Radicals. Plant Biology, 10, 171-184. https://doi.org/10.1111/j.1438-8677.2007.00019.x

[29] Hölzl, G. and Dörmann, P. (2007) Structure and Function of Glycoglycerolipids in Plants and Bacteria. Progress in Lipid Research, 46, 225-243. https://doi.org/10.1016/j.plipres.2007.05.001

[30] Anderson, M.X., Larsson, K.E., Tjellström, H., Liljenberg, C. and Sandelius, A.S. (2005) Phosphate-Limited Oat. The Plasma Membrane and the Tonoplast as Major Targets for Phospholipid-to-Glycolipid Replacement and Stimulation of Phospholipases in the Plasma Membrane. Journal of Biological Chemistry, 280, 27578- 
27586. https://doi.org/10.1074/jbc.M503273200

[31] Block, M.A., Douce, R., Joyard, J. and Rolland, N. (2007) Chloroplast Envelope Membranes: A Dynamic Interface between Plastids and the Cytosol. Photosynthesis Research, 92, 225-244. https://doi.org/10.1007/s11120-007-9195-8

[32] Torres-Franklin, M.-L., Gigon, A., de Melo, D.F., Zuily-Fodil, Y. and Pham-Thi, A.-T. (2007) Drought Stress and Rehydration Affect the Balance between MGDG and DGDG Synthesis in Cowpea Leaves. Physiologia Plantarum, 131, 201-210. https://doi.org/10.1111/j.1399-3054.2007.00943.x

[33] Mosblech, A., König, S., Stenzel, I., Grzeganek, P., Feussner, I. and Heilmann, I. (2008) Phosphoinositide and Inositolpolyphosphate Signalling in Defense Responses of Arabidopsis thaliana Challenged by Mechanical Wounding. Molecular Plant, 1, 249-261. https://doi.org/10.1093/mp/ssm028

[34] Bargmann, B.O.R. and Munnik, T. (2006) The Role of Phospholipase D in Plant Stress Responses. Current Opinion in Plant Biology, 9, 515-522. https://doi.org/10.1016/j.pbi.2006.07.011

[35] Wang, X. and Chapman, K.D. (2013) Lipid Signaling in Plants. Frontiers in Plant Science. https://doi.org/10.3389/978-2-88919-148-2

[36] Kooijman, E.E., Carter, K.M., van Laar, E.G., Chupin, V., Burger, K.N.J. and de Kruijff, B. (2005) What Makes the Bioactive Lipids Phosphatidic Acid and Lysophosphatidic Acid So Special? Biochemistry, 44, 17007-17015. https://doi.org/10.1021/bi0518794

[37] Meijer, H.J.G. and Munnik, T. (2003) Phospholipid-Based Signaling in Plants. Annual Review of Plant Biology, 54, 265-306. https://doi.org/10.1146/annurev.arplant.54.031902.134748

[38] Tayeh, C., Randoux, B., Laruelle, F., Bourdon, N., Renard-Merlier, D. and Reignault, P. (2013) Lipids as Markers of Induced Resistance in Wheat: A Biochemical and Molecular Approach. In: Valenzuela Baez, R., Ed., Lipid Metabolism, IntechOpen. https://doi.org/10.5772/51279

[39] Ohlrogge, J. and Browse, J. (1995) Lipid Biosynthesis. The Plant Cell, 7, 957-970. https://doi.org/10.1105/tpc.7.7.957

[40] Makarenko, S.P., Konenkina, T.A., Suvorova, G.G. and Oskorbina, M.V. (2014) Seasonal Changes in the Fatty Acid Composition of Pinus sylvestris Needle Lipids. Russian Journal of Plant Physiology, 61, 119-123. https://doi.org/10.1134/S1021443713050105

[41] Nishida, I. and Murata, N. (1996) Chilling Sensitivity in Plants and Cyanobacteria: The Crucial Contribution of Membrane Lipids. Annual Review of Plant Physiology and Plant Molecular Biology, 47, 541-568. https://doi.org/10.1146/annurev.arplant.47.1.541

[42] Uemura, M., Tominaga, Y., Nakagawara, C., Shigematsu, S., Minami, A. and Kawamura, Y. (2006) Responses of the Plasma Membrane to Low Temperatures. Physiologia Plantarum, 126, 81-89. https://doi.org/10.1111/j.1399-3054.2005.00594.X

[43] Strimbeck, G.R., Schaberg, P.G., Fossdal, C.G., Schröder, W.P. and Kjellsen, T.D. (2015) Extreme Low Temperature Tolerance in Woody Plants. Frontiers in Plant Science, 6, 884. https://doi.org/10.3389/fpls.2015.00884

[44] Marechal, E., Block, M.A., Dorne, A.-J., Douce, R. and Joyard, J. (1997) Lipid Synthesis and Metabolism in the Plastid Envelope. Physiologia Plantarum, 100, 65-77. https://doi.org/10.1111/j.1399-3054.1997.tb03455.x

[45] Haucke, V. and Di Paolo, G. (2007) Lipids and Lipid Modifications in the Regula- 
tion of Membrane Traffic. Current Opinion in Cell Biology, 19, 426-435. https://doi.org/10.1016/j.ceb.2007.06.003

[46] Basu, M.M., Gonzalez-Carranza, Z.H., Azam-Ali, S., Tang, S., Shahid, A.A. and Roberts, J.A. (2013) The Manipulation of Auxin in the Abscission Zone Cells of Arabidopsis Flowers Reveals That Indoleacetic Acid Signaling Is a Prerequisite for Organ Shedding. Plant Physiology, 162, 96-106. https://doi.org/10.1104/pp.113.216234

[47] MacDonald, M.T., Lada, R.R., Martynenko, A.I., Dorais, M., Pepin, S. and Desjardins, Y. (2011) Ethylene Exposure Duration Affects Postharvest Needle Abscission in Balsam Fir (Abies balsamea L.). HortScience, 46, 260-264. https://doi.org/10.21273/HORTSCI.46.2.260

[48] Scotti-Campos, P., Pais, I.P., Partelli, F.L., Batista-Santos, P. and Ramalho, J.C. (2014) Phospholipids Profile in Chloroplasts of Coffea spp. Genotypes Differing in Cold Acclimation Ability. Journal of Plant Physiology, 171, 243-249. https://doi.org/10.1016/j.jplph.2013.07.007

[49] Bohn, M., Lüthje, S., Sperling, P., Heinz, E. and Dörffling, K. (2007) Plasma Membrane Lipid Alterations Induced by Cold Acclimation and Abscisic Acid Treatment of Winter Wheat Seedlings Differing in Frost Resistance. Journal of Plant Physiology, 164, 146-156. https://doi.org/10.1016/j.jplph.2005.12.008

[50] Partelli, F.L., Batista-Santos, P., Scotti-Campos, P., Pais, I.P., Quartin, V.L., Vieira, H.D. and Ramalho, J.C. (2011) Characterization of the Main Lipid Components of Chloroplast Membranes and Cold Induced Changes in Coffea spp. Environmental and Experimental Botany, 74, 194-204. https://doi.org/10.1016/j.envexpbot.2011.06.001

[51] Shah, J. (2005) Lipids, Lipases, and Lipid-Modifying Enzymes in Plant Disease Resistance. Annual Review of Phytopathology, 43, 229-260. https://doi.org/10.1146/annurev.phyto.43.040204.135951

[52] Sun, J., You, X., Li, L., Peng, H., Su, W., Li, C., He, Q. and Liao, F. (2011) Effects of a Phospholipase D Inhibitor on Postharvest Enzymatic Browning and Oxidative Stress of Litchi Fruit. Postharvest Biology and Technology, 62, 288-294. https://doi.org/10.1016/j.postharvbio.2011.07.001

[53] Bartoli, C.G., Simontacchi, M., Montaldi, E. and Puntarulo, S. (1996) Oxidative Stress, Antioxidant Capacity and Ethylene Production during Ageing of Cut Carnation ( Dianthus caryophyllus ) Petals. Journal of Experimental Botany, 47, 595-601. https://doi.org/10.1093/jxb/47.4.595

[54] Laloi, C., Apel, K. and Danon, A. (2004) Reactive Oxygen Signalling: The Latest News. Current Opinion in Plant Biology, 7, 323-328. https://doi.org/10.1016/j.pbi.2004.03.005

[55] Tintinger, G.R., Steel, H.C., Theron, A.J. and Anderson, R. (2008) Pharmacological Control of Neutrophil-Mediated Inflammation: Strategies Targeting Calcium Handling by Activated Polymorphonuclear Leukocytes. Drug Design, 2, 95-104.

[56] Vu, H.S., Shiva, S., Roth, M.R., Tamura, P., Zheng, L., Li, M., Sarowar, S., Honey, S., McEllhiney, D., Hinkes, P., Seib, L., Williams, T.D., Gadbury, G., Wang, X., Shah, J., Welti, R., et al. (2014) Lipid Changes after Leaf Wounding in Arabidopsis thaliana: Expanded Lipidomic Data Form the Basis for Lipid Co-Occurrence Analysis. The Plant Journal, 80, 728-743. https://doi.org/10.1111/tpj.12659

[57] Wang, X., Devaiah, S., Zhang, W. and Welti, R. (2006) Signaling Functions of Phosphatidic Acid. Progress in Lipid Research, 45, 250-278. https://doi.org/10.1016/j.plipres.2006.01.005 
[58] Ivanova, A., Stefanov, K. and Yordanov, I. (1998) Effect of Cytokinin 4-PU-30 on the Lipid Composition of Water Stressed Bean Plants. Biologia plantarum, 41, 155-159. https://doi.org/10.1023/A:1001797407720

[59] Kull, U., Kühn, B., Schweizer, J. and Weiser, H. (1978) Short-Term Effects of Cytokinins on the Lipid Fatty Acids of Green Leaves. Plant and Cell Physiology, 19, 801-810. https://doi.org/10.1093/oxfordjournals.pcp.a075654

[60] Dörmann, P. (2013) Galactolipids in Plant Membranes. John Wiley \& Sons, Ltd., Chichester. https://doi.org/10.1002/9780470015902.a0020100.pub2

[61] Pospislová, J., Synková, H. and Rulcová, J. (2000) Cytokinins and Water Stress. Biologia Plantarum, 43, 321-328. https://doi.org/10.1023/A:1026754404857

[62] Chen, H.-J., Bollmark, M. and Eliasson, L. (1996) Evidence That Cytokinin Controls Bud Size and Branch Form in Norway Spruce. Physiology Plantarum, 98, 612-618. https://doi.org/10.1111/j.1399-3054.1996.tb05718.x

[63] Sun, J., Cardoza, V., Mitchell, D.M., Bright, L., Oldroyd, G. and Harris, J.M. (2006) Crosstalk between Jasmonic Acid, Ethylene and Nod Factor Signaling Allows Integration of Diverse Inputs for Regulation of Nodulation. The Plant Journal, 46, 961-970. https://doi.org/10.1111/j.1365-313X.2006.02751.x

[64] Gfeller, A., Dubugnon, L., Liechti, R. and Farmer, E. (2010) Jasmonate Biochemical Pathway. Science Signaling, 3, cm3. https://doi.org/10.1126/scisignal.3109cm3

[65] Burnette, R.N. (2003) An Arabidopsis Inositol 5-Phosphatase Gain-of-Function Alters Abscisic Acid Signaling. Plant Physiology, 132, 1011-1019.

https://doi.org/10.1104/pp.019000

[66] Browse, J. (2005) Jasmonate: An Oxylipin Signal with Many Roles in Plants. Vitamins \& Hormones, 72, 431-456. https://doi.org/10.1016/S0083-6729(05)72012-4

[67] Kachroo, A. and Kachroo, P. (2009) Fatty Acid-Derived Signals in Plant Defense. Annual Review of Phytopathology, 47, 153-176. https://doi.org/10.1146/annurev-phyto-080508-081820

[68] Peterson, K.M., Rychel, A.L. and Torii, K.U. (2010) Out of the Mouths of Plants: The Molecular Basis of the Evolution and Diversity of Stomatal Development. The Plant Cell, 22, 296-306. https://doi.org/10.1105/tpc.109.072777

[69] Mazliak, P. (1983) Plant Membrane Lipids: Changes and Alterations during Aging and Senescence. In: Lieberman, M., Ed., Post-Harvest Physiology and Crop Preservation, Springer, Boston, MA.

[70] Kar, R.K. (2011) Plant Responses to Water Stress: Role of Reactive Oxygen Species. Plant Signaling \& Behavior, 6, 1741-1745. https://doi.org/10.4161/psb.6.11.17729

[71] Okazaki, Y. and Saito, K. (2014) Roles of Lipids as Signaling Molecules and Mitigators during Stress Response in Plants. The Plant Journal, 79, 584-596. https://doi.org/10.1111/tpj.12556

[72] Li, M., Hong, Y. and Wang, X. (2009) Phospholipase D- and Phosphatidic Acid-Mediated Signaling in Plants. Biochimica et Biophysica Acta (BBA)-Molecular and Cell Biology of Lipids, 1791, 927-935.

https://doi.org/10.1016/j.bbalip.2009.02.017

[73] Alferez, F., Singh, S., Umbach, A.L., Hockema, B. and Burns, J.K. (2005) Citrus Abscission and Arabidopsis Plant Decline in Response to 5-Chloro-3-Methyl4-Nitro-1 $H$-Pyrazole Are Mediated by Lipid Signalling. Plant, Cell and Environment, 28, 1436-1449. https://doi.org/10.1111/j.1365-3040.2005.01381.x

[74] Munnik, T. (2001) Phosphatidic Acid: An Emerging Plant Lipid Second Messenger. Trends in Plant Science, 6, 227-233. https://doi.org/10.1016/S1360-1385(01)01918-5 
[75] Munnik, T. and Testerink, C. (2009) Plant Phospholipid Signaling: "In a Nutshell." Journal of Lipid Research, 50, S260-S265. https://doi.org/10.1194/jlr.R800098-JLR200

[76] Thiagarajan, A. (2012) Physiology of Low Temperature-Modulated Postharvest Needle Senescence and Abscission in Balsam Fir (Abies balsamea L.). Ph.D. Thesis, Laval University, Quebec.

[77] Murphy, A.S., Peer, W. and Schulz, B. (2011) The Plant Plasma Membrane. Springer, Heidelberg, New York. https://doi.org/10.1007/978-3-642-13431-9

[78] Oude Weernink, P.A., López de Jesús, M. and Schmidt, M. (2007) Phospholipase D Signaling: Orchestration by $\mathrm{PIP}_{2}$ and Small GTPases. Naunyn-Schmiedeberg's Archives of Pharmacology, 374, 399-411. https://doi.org/10.1007/s00210-007-0131-4

[79] Howe, G. (2004) Jasmonates. In: Davies, P., Ed., Plant Hormones: Biosynthesis, Signal Transduction, Action, Kluwer Academic Publishers, Boston, MA.

[80] Engelberth, J. (2011) Jasmonates and Other Fatty Acid-Derived Signaling Pathways in the Plant Defense Response. In: Zeiger, T. and Murphy, M., Eds., Plant Physiology and Development, 6th Edition, Sinauer Associates, Inc., Sunderland, MA.

[81] Schaller, A. and Stintzi, A. (2009) Enzymes in Jasmonate Biosynthesis-Structure, Function, Regulation. Phytochemistry, 70, 1532-1538. https://doi.org/10.1016/j.phytochem.2009.07.032

[82] Schmelz, E., Alborn, H., Banchio, E. and Tumlinson, J. (2003) Quantitative Relationships between Jasmonic Acid Levels and Volatile Emission in Zea mays during Spodoptera exigua Herbivory. Planta, 216, 665-673.

[83] Onkokesung, N., Galis, I., von Dahl, C.C., Matsuoka, K., Saluz, H.-P. and Baldwin, I.T. (2010) Jasmonic Acid and Ethylene Modulate Local Responses to Wounding and Simulated Herbivory in Nicotiana attenuata Leaves. Plant Physiology, 153, 785-798. https://doi.org/10.1104/pp.110.156232

[84] Hudgins, J.W. and Franceschi, V.R. (2004) Methyl Jasmonate-Induced Ethylene Production Is Responsible for Conifer Phloem Defense Responses and Reprogramming of Stem Cambial Zone for Traumatic Resin Duct Formation. Plant Physiolo$g y$, 135, 2134-2149. https://doi.org/10.1104/pp.103.037929

[85] Daszkowska-Golec, A. and Szarejko, I. (2013) Open or Close the Gate-Stomata Action under the Control of Phytohormones in Drought Stress Conditions. Frontiers in Plant Science, 4, 138. https://doi.org/10.3389/fpls.2013.00138

[86] Daszkowska-Golec, A. and Szarejko, I. (2013) The Molecular Basis of ABA-Mediated Plant Response to Drought. In: Vahdati, K., Ed., Abiotic Stress-Plant Responses and Applications in Agriculture, InTech. https://doi.org/10.5772/53128

[87] Sharp, R.E. and LeNoble, M.E. (2002) ABA, Ethylene and the Control of Shoot and Root Growth under Water Stress. Journal of Experimental Botany, 53, 33-37. https://doi.org/10.1093/jexbot/53.366.33

[88] Gómez-Cadenas, A., Tadeo, F.R., Talon, M. and Primo-Millo, E. (1996) Leaf Abscission Induced by Ethylene in Water-Stressed Intact Seedlings of Cleopatra Mandarin Requires Previous Abscisic Acid Accumulation in Roots'. Plant Physiology, 112, 401-408. https://doi.org/10.1104/pp.112.1.401

[89] Zacarias, L. and Reid, M.S. (1990) Role of Growth Regulators in the Senescence of Arabidopsis thaliana Leaves. Physiologia Plantarum, 80, 549-554. https://doi.org/10.1111/j.1399-3054.1990.tb05677.x

[90] Xia, X.-J., Zhou, Y.-H., Shi, K., Zhou, J., Foyer, C.H. and Yu, J.-Q. (2015) Interplay between Reactive Oxygen Species and Hormones in the Control of Plant Develop- 
ment and Stress Tolerance. Journal of Experimental Botany, 66, 2839-2856. https://doi.org/10.1093/jxb/erv089

[91] Bailey-Serres, J. and Mittler, R. (2006) The Roles of Reactive Oxygen Species in Plant Cells. Plant physiology, 141, 311-311. https://doi.org/10.1104/pp.104.900191

[92] Anjum, N.A., Sofo, A., Scopa, A., Roychoudhury, A., Gill, S.S., Iqbal, M., Lukatkin, A.S., Pereira, E., Duarte, A.C. and Ahmad, I. (2015) Lipids and Proteins-Major Targets of Oxidative Modifications in Abiotic Stressed Plants. Environmental Science and Pollution Research, 22, 4099-4121. https://doi.org/10.1007/s11356-014-3917-1

[93] Droillard, M.-J., Bureau, D. and Paulin, A. (1989) Changes in Activities of Superoxide Dismutases during Aging of Petals of Cut Carnations (Dianthus caryophyllus). Physiologia Plantarum, 76, 149-154. https://doi.org/10.1111/j.1399-3054.1989.tb05624.x

[94] Song, Y., Miao, Y. and Song, C.-P. (2014) Behind the Scenes: The Roles of Reactive Oxygen Species in Guard Cells. New Phytologist, 201, 1121-1140. https://doi.org/10.1111/nph.12565

[95] Fan, L., Zheng, S. and Wang, X. (1997) Antisense Suppression of Phospholipase D $\alpha$ Retards Abscisic Acid- and Ethylene-Promoted Senescence of Postharvest Arabidopsis Leaves. The Plant Cell, 9, 2183-2196. https://doi.org/10.2307/3870578

[96] Sakamoto, M., Munemura, I., Tomita, R. and Kobayashi, K. (2008) Involvement of Hydrogen Peroxide in Leaf Abscission Signaling, Revealed by Analysis with an in Vitro Abscission System in Capsicum Plants. The Plant Journal, 56, 13-27. https://doi.org/10.1111/j.1365-313X.2008.03577.x

[97] Scherer, G.F.E. (1996) Auxin Activation of Phospholipase $A_{2}$ Generated Lipids, and the Function of Lipid-Activated Protein Kinase. In: Smith, A.R., Berry, A.W., Harpham, N.V.J., Moshkov, I.E., Novikova, G.V., Kulaeva, O.N. and Hall, M.A., Eds., Plant Hormone Signal Perception and Transduction, Springer, Dordrecht, Netherlands, 185-189. https://doi.org/10.1007/978-94-009-0131-5_25

[98] Morgan, P.W. and Drew, M.C. (1997) Ethylene and Plant Responses to Stress. Physiologia Plantarum, 100, 620-630. https://doi.org/10.1111/j.1399-3054.1997.tb03068.x

[99] Gangwar, S., Singh, V.P., Prasad, S.M. and Maurya, J.N. (2012) Exogenous Application of Indole Acetic Acid Differentially Modulates Hexavalent Chromium Tolerance in Pisum sativum L. Seedlings. Bulletin of Environmental and Scientific Research, 1, 1-11.

[100] Xiong, L. and Zhu, J.-K. (2001) Abiotic Stress Signal Transduction in Plants: Molecular and Genetic Perspectives. Physiologia Plantarum, 112, 152-166. https://doi.org/10.1034/j.1399-3054.2001.1120202.x

[101] Koo, A.J.K., Chung, H.S., Kobayashi, Y. and Howe, G.A. (2006) Identification of a Peroxisomal Acyl-Activating Enzyme Involved in the Biosynthesis of Jasmonic Acid in Arabidopsis. Journal of Biological Chemistry, 281, 33511-33520. https://doi.org/10.1074/jbc.M607854200

[102] Daintith, J. (2008) A Dictionary of Chemistry. 6th Edition, Oxford University Press, New York.

[103] Hong, Y., Zhang, W. and Wang, X. (2010) Phospholipase D and Phosphatidic Acid Signalling in Plant Response to Drought and Salinity. Plant, Cell \& Environment, 33, 627-635. https://doi.org/10.1111/j.1365-3040.2009.02087.x 